\title{
Intraoperative Frozen Section Analysis - A Study of Tertiary Care Centre
}

\section{IJCRR}

Section: Healthcare

ISI Impact Factor

(2019-20): 1.628

IC Value (2019): 90.81

$\operatorname{SJIF}(2020)=7.893$

(c) (7) (8)

Copyright@IJCRR

\section{Prajapati Jagdish Arvindbhai ${ }^{1}$, Parikh Biren Pravinchandra ${ }^{2}$}

'Assistant Professor, Parul Institute of Medical Sciences and Research (PIMSR), Waghodiya, Vadodara (Ex Fellow in Oncopathology, The Gujarat Cancer and Research Institute, Ahmedabad, India; ${ }^{2}$ Associate Professor in Oncopathology, The Gujarat Cancer and Research Institute, Ahmedabad, India.

\section{ABSTRACT}

Intraoperative Frozen Section Analysis- A Study of the tertiary care centre

Introduction: Frozen section (FS) is a key Histopathological technique used by pathologists during intraoperative consultation which will help operate surgeon to decide resection intraoperatively. FS is a rapid technique to evaluate tissue diagnosis, margins and lymph node metastasis. The present study aims to evaluate the accuracy, sensitivity and specificity of the frozen section with error rates of FS in our institute.

Methods and Material: The present study was carried out at the Histopathology section of the department of Oncopathology at the tertiary care centre from 1st January 2018 to 31st December 2018. The data was obtained from our online Laboratory Information System (LIS). Fresh tissue was received in a clean sterile container. Gross examination and sectioning were done and the further procedure has been carried out in Cryostat. Rapid Haematoxylin and eosin staining were performed and slides were prepared. Statistical analysis was performed using Statistical Package for the Social Science Software (SPSS).

Results: In the present study, the overall accuracy rate, sensitivity, specificity, positive predictive value (PPV) and negative predictive value (NPV) were 94.93\%, 98.96\%, 91.17\%, 92.13\% and 98.96\% respectively. The discordance rate was 5.07\%.

Conclusions: Frozen section is a reliable, accurate and rapid technique for intraoperative consultation which will help operate surgeons. Regular evaluation of discordance rate and analysis of methodology with technical skills will improve the accuracy rate of FS.

Key Words: Intraoperative consultation, Histopathology, Accuracy rate, Sensitivity, Specificity, Discordant rate

\section{INTRODUCTION}

Frozen section (FS) evaluation is a key Histopathological technique used by pathologists during intraoperative consultation. ${ }^{1}$ The beginning of this intraoperative diagnosis began with a publication by Louis B Wilson, MD at the Mayo clinic in $1905 .^{2} \mathrm{FS}$ is a rapid technique that contributes to the primary diagnosis like benign, malignant or inflammatory lesion. It also indicated to evaluate margins, lymph node metastasis and to determine nature of lesion that may require the ancillary test. ${ }^{3,4}$

The primary aims and objectives of the present study are to know

(1) Accuracy, sensitivity and specificity of FS

(2) Error rates of FS in our institute

\section{MATERIAL AND METHOD}

The present study was carried out at the Histopathology section of the department of Oncopathology at the tertiary care centre from $1^{\text {st }}$ January 2018 to $31^{\text {st }}$ December 2018. It is a hospital record-based retrospective cross-sectional study. During this study, a total of 1015 specimens and biopsies were received for intra-operative pathological consultation for various malignant and non-malignant conditions. Out of 1015 cases, 9 cases were deferred due to inadequate material or non-representative tissue. In the present study, a total of 1006 cases was included for statistical analysis. The data was obtained from our online Laboratory Information system (LIS). Fresh tissue samples were received in a clean sterile and properly labelled container along with a test requisition form (TRF), which carries necessary clinical

Corresponding Author:

Parikh Biren Pravinchandra, Associate Professor in Oncopathology, The Gujarat Cancer and Research Institute, Ahmedabad, India. Phone: 9773114484; Email: birenparikh2002@rediffmail.com

ISSN: 2231-2196 (Print)

Received: 04.01 .2021
ISSN: 0975-5241 (Online)

Revised: 26.02 .2021
Accepted: 18.04 .2021
Published: 12.09 .2021 
details and indications. An appointment for an FS consultation was usually fixed on the previous day by the surgical departments requesting for the investigation. Patients of all age groups with no sex predilection were included in the present study. Grossing of received specimens were done and submitted for further procedure and analysis. Imprint smear and squash smears were taken in required cases. During the procedure cryostat (SLEE) temperature was kept at $-18^{\circ} \mathrm{c}$ to $-24^{\circ} \mathrm{c}$ depending upon the nature of the tissue. The clearance angle was set at $10^{\circ} \mathrm{c}$. Polyethylene-Glycol (PEG) compound was the freezing medium used and was poured onto chucks. When the medium and tissue were frozen, the chuck was inserted into the clamping lever and was fixed. Sections were cut at 4-5 $\mu$ thickness and were immediately fixed in 95\% isopropyl alcohol. Two-three sections per slide and 2 slides were prepared from each block. Rapid haematoxylin and eosin (H\&E) staining was performed. Frozen section diagnosis was made by a senior pathologist. Frozen sections were analysed for tissue diagnosis, surgical margins and lymph node metastasis. It was immediately conveyed to the operating surgeon through telephonic conversation as well as by an electronically signed report.

For routine buffered formalin-fixed paraffin embedding (FFPE) tissue processing: The remaining tissue from the FS specimen received for Histopathology was fixed in $10 \%$ neutral buffered formalin. Grossing was done and sections were taken from representative areas. Conventional Histopathology was performed in a fully automated tissue processor (Thermo Shandon). The paraffin-embedded sections were cut at $4 \mu$ and were stained by routine H\&E staining technique in automatic stainer by Leica and followed by Immunohistochemistry (fully automated, Ventana) whenever needed. The impression of the pathologist as given to the surgeon at the time of surgery was compared to the final Histopathology report of the permanent sections.

Concordant vs discordant cases: Concordant cases were those where the diagnosis of frozen section matched with the final histopathological diagnosis. The discordant cases were those in which incorrect or equivocal assessment adversely affect the intraoperative management.

\section{STATISTICAL METHOD}

Statistical analysis was performed using Statistical Package for the Social Science (SPSS) software. The results were obtained as concordant and discordant cases. The results were further classified into the following categories: true negative (absence of tumour correctly diagnosed), true positive (presence of tumour correctly diagnosed), false positive (the cytological or frozen section was incorrectly diagnosed as a tumour), false negative (the cytological or frozen section specimen failed to diagnose as the tumour), accuracy rate, sensitivity, specificity, PPV (Positive predictive value) NPV (Negative predictive value).

\section{RESULTS}

In this group of 1006 patients, 546 were male and 460 were female. Male to Female ratio is 1.2:1.

The most common indications of FS in our institute were:

(1) Primary diagnosis - 579 cases $(57.5 \%)$

(2) Assessment of margins of tumour excision - 398 cases $(39.7 \%)$

(3) Assessment of nodal status mainly in Head \& Neck $(\mathrm{H} \& \mathrm{~N})$ and Breast malignancies -29 cases $(2.8 \%)$

The commonest unit from which tissue was submitted for FS analysis was H\&N (429 cases, 42.64\%) followed by Neurology (308 cases, 30.62\%) and Gynaecology (10 cases, $10.93 \%)$.

The total concordance cases were 955 (94.93\%) which includes true positive 480 cases $(47.71 \%)$ and true negative 475 cases (47.21\%). Total discordant cases were 51 (5.07\%). False-positive cases (46 cases) were more common than false-negative cases (05 cases) (Table I).

The overall accuracy rate was $94.93 \%$. Sensitivity was 98.96\% among all cases. Specificity was highest for benign cases $(96.02 \%)$. The overall positive predictive value was $92.13 \%$ and the negative predictive value was $98.96 \%$ (Table II).

In the present study, a total of 1006 cases of FS analysis includes benign cases, borderline cases, malignant cases, margins, lymph nodes and no pathology in tissue. We have reported no pathology in 480 cases $(47.7 \%)$. Out of that 5 cases were turned out to be malignant in permanent sections (Table III).

The commonest discordant cases were found in H\&N (31 cases) followed by Neurology (12 cases) (Table IV).

\section{DISCUSSION}

The frozen section is generally considered an accurate and reliable method of diagnosis which helps surgeons in deciding further intraoperative courses. Intraoperative frozen section evaluation for initial diagnosis, margin status and lymph node status or confirmation of prior diagnosis has become a common procedure. It is relatively expensive and technically limited, thus available only in major hospitals and diagnostics centres. It also requires highly trained technical staff, adequate equipment and workload. Pathologists must be trained for frozen section reporting. Technicians require more skill in the frozen section than the paraffin-embedded 
section. The frozen section guides the surgeons to avoid undertreatment or overtreatment. The pathologist must know the usefulness and limitations of frozen sections along with the limitation of technical staff. Pathologists also need details of clinical history, site, size of the lesion, any previous treatment like chemotherapy or radiotherapy along with radiological findings. So, frozen section reporting requires good teamwork. Long term monitoring of FS-permanent section correlation is associated with sustained performance improvement. ${ }^{5}$ The frozen section diagnosis can be benign, borderline lesion, malignant, free of tumour or no pathology at the oncology centre. The frozen section is also important in ensuring adequate margin clearance. . $^{6,78}$

In the available literature, the deferral rate varies from 0 to $6.1 \%$. ${ }^{9,10}$ Selvakumar et al. study has a deferred rate of $2.27 \%{ }^{4}$ However, in the present study deferred rate was $0.8 \%$. The overall accuracy rate of frozen section diagnosis in the literature varying from $92 \%$ to $97.98 \%$. $^{10,11,12}$

In the present study, an overall accuracy rate of $94.93 \%$. The sensitivity of the frozen section reported in various studies ranges from $84.6 \%$ to $97.98 \%$. ${ }^{11,12,13}$ In the present study, observed sensitivity of $98.96 \%$ which also falls within the range. The reported specificity of frozen sections in the literature ranges from $94.55 \%$ to $100 \% .^{11,12,13}$ In the present study observed specificity of $91.17 \%$, which is near about the lower range of reported specificity of literature ranges. In the present study, observed sensitivity was $84.86 \%$ in benign cases and $95.7 \%$ in malignant cases while specificity in benign cases was $96.02 \%$ and $85.2 \%$ in malignant cases. We have compared the overall sensitivity, specificity of the accuracy of frozen sections with the other studies from India and different parts of the world (Table V).

Likelihood ratio (LR) is the probability of that finding in patients with disease divided by the probability of the same finding in patients without the disease. Positive LRs increase the probability of disease and negative LRs decrease the probability of disease. ${ }^{15}$ In the present study, FS indicates a high increase in the likelihood of the disease as LR+ was 10.28. $(\mathrm{LR}+>10)$. Also, $\mathrm{LR}-$ value is $0.011(\mathrm{LR}<0.1)$ this indicate that the frozen section has been effective in indicating a reduction in the likelihood of the disease. The LR values are comparable to Nayanar et al. and Carvalho et al. ${ }^{1,16}$

The literature reports discordance rates ranging from $1.4 \%$ to $12.9 \%$ in different anatomical sites. ${ }^{17,18,19}$ In the present study discordant rate was $5.07 \%$. In the present study, out of 51 discordant cases, 35 (68.62\%) cases are of H\&N (31 cases) and Breast $\&$ Thorax unit (4 cases). Of which seven $(20.0 \%)$ cases are false-negative and $28(80.0 \%)$ cases are false positive. Studies have shown that the frozen section is important and highly effective in avoiding re-operations. ${ }^{14,23}$ In $\mathrm{H} \& \mathrm{~N}$ and Breast \& Thorax, margins clearance is crucial as chances of recurrence are high and difficult to treat, ${ }^{24}$ So in $\mathrm{H} \& \mathrm{~N}$ and Breast \& Thorax, a false negative is more costly during intraoperative frozen section analysis as it will lead to recurrences and repeat surgeries.

In the present study, out of 51 discordant cases, 12 (23.52\%) cases were of the Neurology unit. Seven $(58.33 \%)$ cases are of false negative for a malignant tumour in the frozen section and $5(41.67 \%)$ cases are of false-positive because of freezing artefact and experience of pathologist dealing with the Neurology specimen. Soft and edematous nature of Neurology specimen, freezing artefact alters the cellular and nuclear morphology leads to misinterpretation. ${ }^{3}$

Three cases were reported negative for malignancy in the frozen section in case of the Orthopaedics unit, which was positive for malignancy in the paraffin section. These were due to inadequate tissue received for frozen and lack of communication to orthopaedics for clinical-radiological findings which again helpful for diagnosis of bone tumours. Additional tissue material was received after FS which were processed and the final diagnosis was made on the paraffin section.

In the present study, out of 51 discordant cases, one case was of the Gynaecology unit. In frozen mucinous neoplasm- borderline was reported which turned out to be well-differentiated mucinous adenocarcinoma on paraffin section. The cause for this false-negative diagnosis was inadequate sampling or may be due to the focal nature of the lesion. Misdiagnosis can be the result of lack of communication between the clinician and pathologist, false interpretation, improper and inadequate sampling. ${ }^{25,26}$ The leading causes which can affect the frozen section are sampling error due to improper sampling, technical error and interpretation error done by pathologists. ${ }^{27,28}$ The type of error varies in each study depending upon the method used for freezing, type of specimen most commonly received, type of procedure adopted and focal nature of the lesion..$^{29}$ Many studies have concluded that disagreement in FS diagnosis is mostly due to interpretation and sampling error, followed by sectioning, inadequate history, staining and labelling., ${ }^{3,18,30}$ Out of 51 cases, 19 (37.25\%) cases were due to interpretation error and the remaining 32 $(62.75 \%)$ cases were due to inadequate sampling and sectioning. Interpretation errors include morphological changes due to freezing, lack of technical staff experience and experience of pathologists dealing with FS.

The average turnaround time (TAT) required for the entire frozen section procedure varies from 20 to 25 minutes. ${ }^{31}$ The average turnaround time observed in the present study is 20 30 minutes, which is comparable with the range reported by other studies.

\section{CONCLUSION}

The frozen section is a reliable, accurate and rapid technique for intraoperative consultation. The frozen section has its 
value which should be remembered by both pathologists and surgeons. The frozen section is an important method in $\mathrm{H} \& \mathrm{~N}$ to evaluate the status of margins as it is very crucial to avoid repeat surgery, chances of recurrences and also to decide for further procedure. Also helpful in Breast conservative surgery (BCS)/lumpectomy specimens to evaluate sentinel lymph node intraoperatively to check for metastasis of lymph node and further axillary lymph node dissection (ALND).

Regular audit and analysis of methodology, technical skills, clinicopathological discussion and adequate sectioning are important factors to improve frozen section reliability in the pathology department. Evaluation of discordant rate regularly with experience of the pathologist in the frozen section will improve the accuracy of frozen section diagnosis and thus patient management.

\section{ACKNOWLEDGEMENT}

Authors acknowledge the immense help received from the scholars whose articles are cited and included in references of this manuscript. The authors are also grateful to authors whose articles from where the literature for this article has been reviewed.

\section{Source of funding: None}

\section{Conflict of interest: None}

Author's contribution: Both authors have contributed to the planning, implementation and analysis of the research study and its presentation in the form of the manuscript.

Ethical clearance Letter No: IRC/2019/P-106

\section{REFERENCES}

1. Nayanar SK, Aswathi KM, Mrudula KI, Thavarool SB, Thiagarajan S. Frozen section evaluation in Head and neck Oncosurgery: An initial Experience in a Tertiary Cancer Centre. Turk PatolojiDerg 2019; 35:046-51.

2. Ryan J, Baker L, Editors. Dordrecht. Recent concepts in sarcoma treatment. Springer Netherlands 1988:81-8.

3. Patil P, Shukla S, Bhake A, Hiwale K. Accuracy of frozen section analysis in correlation with surgical pathology diagnosis. Int J Res Med Sci 2015;3:399-04.

4. Selvakumar AS, Rajalakshmi V, Sundaram, KM. Intraoperative frozen section consultation- an audit in a tertiary care hospital. Indian J Pathol 2018;5:421-28.

5. Raab SS, Tworek JA, Souers R, Zarbo RJ. The value of monitoring frozen section-permanent section correlation data over time. Arch Pathol Lab Med 2006;130:337-42.

6. Hatami H, Mohsenifar Z, Alavi SN. The diagnostic accuracy of frozen section compared to the permanent section: A singlecentre study in Iran. Iran J Pathol 2015;10:295-99.

7. Olson SM, Hussaini M, Lewis JS Jr. Frozen section analysis of margins for head and neck tumor resections: reduction of sampling errors with a third histologic level. Mod Pathol 2011;24:665-70.

8. Esbona K, LiZ, Wilke LG. Intraoperative imprint cytology and frozen section pathology for margin assessment in breast conservation surgery: a systematic review. Ann Surg Oncol 2012;19:3236-45.

9. Khoo JJ. An audit of intraoperative frozen section in Johor. Med J Malaysia 2004;59:50-5.

10. Oneson RH, Minke JA, Silverberg SG. Intraoperative Pathologic Consultation. An audit of 1,000 recent consecutive cases. Am J Surg Pathol 1989;13:237-43.

11. Chang J-L, Tseng H-H, Sheru L-F, Lee W-H, Tu Y-C. Diagnostic accuracy of frozen section in a surgical pathology-a retrospective analysis of 1084 frozen sections. J Med Sci 1992;13:133-42.

12. Farah-Klibi F, Neji O, Ferjaoui M, Zaouche A, Koubaa A, Sfar R et al. Accuracy of frozen section diagnosis: an analysis of 1695 consecutive cases. Tunis Med 2008;86:693-97.

13. Shrestha S, Lee MC, Dhakal H, Pun CB, Pradhan M, Shrestha S et al. Comparative Study of frozen section Diagnoses with Histopathology. Postgrad. Med. J of NAMS 2009;3:1-5.

14. Abbasi F, Yekta Z, Aryan A. Accuracy of frozen sections. Iranian J Pathol 2012;7(1):3-8.

15. McGee S. Simplifying Likelihood Ratios. J Gen Intern Med 2002;17:647-50.

16. Carvalho MB, Soares JM, Rapoport A, Andrade SJ, Fava AS, Kanda JL et al. Perioperative frozen section examination in parotid gland tumors. Sao Paulo Med J 1999;117:233-37.

17. Ozdamar SO, Bahadir B, Ekem TE, Kertis G, Dogan B, Numanoglu $\mathrm{G}$ et al. Frozen section experience with emphasis on reasons for discordance. Turkish Journal of cancer 2006;36:15761.

18. Mahe E, Ara S, Bishara M, Kurian A, Tauqir S, Ursani N et. al. Intraoperative pathology consultation: error, cause and impact. Can J Surg 2013;56:E13-18.

19. da Silva RD, Souto LR, Matsushita GdeM, Matsushita MdeM. Diagnostic accuracy of frozen section tests for surgical diseases. Rev Col Bras Cir. 2011;38:149-54.

20. Ahmad Z, Barakzai MA, Idrees R, Bhurgri Y. Correlation of intraoperative frozen section consultation with the final diagnosis at a referral centre in Karachi, Pakistan. Indian J Pathol Microbiol 2008;51:469-73.

21. Chbani L, Mohamed S, Harmouch T, Fatemi HE, Amarti A. Quality assessment of intraoperative frozen section: an analysis of 261 consecutive cases in a resource-limited area: Morocco. Health 2012;4:433-35.

22. Roy S, Parwani AV, Dhir R, Yousem SA, Kelly SM, Pantanowitz L. Frozen section diagnosis Is there discordance between what pathologists say and what surgeons hear? Am J Clin Pathol 2013;140:363-69.

23. Jorns JM, Visscher D, Sabel M, Breslin T, Healy P, Daignauts S et al. Intraoperative frozen section analysis of margin in breastconserving surgery significantly decreases reoperative rates: One year experience at an ambulatory surgical centre. Am J Clin Pathol 2012;138:657-69.

24. Hosseini M, Alizadeh Otaghvar HR, Tizmaghz A, Shabestanipour G, Arvaneh S. Evaluating the accuracy of fine-needle aspiration and frozen section based on permanent histology in patients with follicular lesions. Med J Islam Repub Iran 2015;29:239.

25. Jaafar H. Intra-operative frozen section consultation: Concepts, applications and limitations. Malays J Med Sci 2006;13:4-12.

26. Gol M, Baloglu A, Yigit S, Dogan M, Aydin C, Yensel U. Accuracy of frozen section diagnosis in ovarian tumours. is there a change over time? Int J Gynecol Cancer 2003;13:593-97. 
27. Wootipoom V, Dechsukhum C, Hanprasetpong J, Lim A. Accuracy of intraoperative frozen section in the diagnosis of ovarian tumours. J Med Assoc Thai 2006;89:577-82.

28. Mohammed AB, Ahuja VK, Farghaly H. Role of frozen section in the intraoperative management of ovarian masses. Middle East Fertil Soc J 2014;20:97-101.

29. Tangjitagamol S, Jesadapatrakul S, Manusirivithaya S, Sheanakul C. Accuracy of frozen section in diagnosis of ovarian mass. Int J Gynecol Cancer 2004;14:212-19.
30. Evans CA, Suvarna SK. Intraoperative diagnosis using frozen section technique. J Clin Pathol 2006;59:334.

31. Novis DA, Zarbo RJ. Interinstitutional comparison of frozen section turnaround time. A college of American Pathologists QProbes study of 32868 frozen sections in 700 hospitals. Arch Pathol Lab Med 1997;121:559-67.

Table I: Overview of result

\begin{tabular}{|c|c|c|c|}
\hline Cases & Disease in Paraffin section & $\begin{array}{c}\text { Non disease in Paraffin sec- } \\
\text { tion }\end{array}$ & Total \\
\hline Positive in Frozen section & $\begin{array}{c}480 \text { (True Positive) } \\
\quad(47.71 \%)\end{array}$ & $\begin{array}{c}46 \text { (False Positive) } \\
(4.57 \%)\end{array}$ & $\begin{array}{c}526 \\
(52.28 \%)\end{array}$ \\
\hline Negative in Frozen section & $\begin{array}{c}05 \text { (False Negative) } \\
(0.51 \%)\end{array}$ & $\begin{array}{l}475 \text { (True Negative) } \\
(47.21 \%)\end{array}$ & $\begin{array}{c}480 \\
(47 \cdot 72 \%)\end{array}$ \\
\hline Total & $\begin{array}{c}485 \\
(48.21 \%)\end{array}$ & $\begin{array}{c}521 \\
(51.79 \%)\end{array}$ & $\begin{array}{l}1006 \\
(100 \%)\end{array}$ \\
\hline
\end{tabular}

Table II: Diagnostic value of frozen section in terms of sensitivity, specificity, PPV, NPV and likelihood ratio.

\begin{tabular}{lccc} 
Statistical Value (\%) & $\begin{array}{c}\text { Benign (\%) } \\
\mathbf{n}=\mathbf{1 9 7}\end{array}$ & $\begin{array}{c}\text { Malignant } \\
\mathbf{n}=323\end{array}$ & $\begin{array}{c}\text { Overall (\%) } \\
\mathbf{n}=\mathbf{1 0 0 6}\end{array}$ \\
Accuracy & 93.9 & 89.78 & 94.93 \\
Sensitivity & 84.86 & 95.70 & 98.96 \\
Specificity & 96.02 & 85.20 & 91.17 \\
Positive predictive value (PPV) & 93.90 & 89.78 & 92.13 \\
Negative predictive value (NPV) & 89.78 & 93.59 & 98.96 \\
+ve Likelihood ratio & 21.21 & 6.46 & 10.28 \\
-ve Likelihood ratio & 0.157 & 0.050 & 0.011 \\
\hline
\end{tabular}

Table III: Comparison of frozen section and final diagnosis $(\mathbf{n}=1006)$.

\begin{tabular}{lccccc} 
Frozen report & Benign & Borderline & Malignant & No pathology & Total (Frozen section) \\
Benign & 185 & - & 12 & - & 197 \\
Borderline & - & 5 & 1 & - & 6 \\
Malignant & 5 & - & 290 & 28 & 323 \\
No Pathology & - & - & 5 & 475 & 480 \\
Total(Paraffin section) & 190 & 5 & 308 & 503 & 1006 \\
\hline
\end{tabular}

Table IV: Discordant cases $(\mathbf{n}=\mathbf{5 1})$

\section{Discordant cases}

$\mathrm{H} \& \mathrm{~N}$

Breast and thorax

Gynaecology

Neurology

Orthopaedics

Total

\section{Number of Cases (\%)}

$$
\begin{gathered}
31(60.78) \\
04(7.8) \\
01(1.9) \\
12(23.52) \\
03(6.0) \\
51(100)
\end{gathered}
$$


Table V: Comparison of various studies with present study on overall accuracy, sensitivity and specificity

\begin{tabular}{lcccccc} 
Name of study & Country & Study Period & $\begin{array}{c}\text { Number of } \\
\text { Cases }\end{array}$ & $\begin{array}{c}\text { Sensitivity } \\
(\%)\end{array}$ & $\begin{array}{c}\text { Specificity } \\
(\%)\end{array}$ & $\begin{array}{c}\text { Accuracy } \\
(\%)\end{array}$ \\
\hline Farah-Klibi F. et al. ${ }^{12}$ & France & 3 & 1207 & 84.6 & 99.8 & 97.5 \\
Fariba Abbasi et al. ${ }^{14}$ & Iran & 7 & 200 & 93.1 & 97.7 & 96.5 \\
Jun-Liang et al." & China & 1 & 1084 & 96.16 & 99.43 & 97.7 \\
Patil et al. & India & 2 & 100 & 97.23 & 96.30 & 96.96 \\
Shrestha et al. & India & 5 & 404 & 94.56 & 94.5 & 94.6 \\
Present study & India & 1 & 1006 & 98.96 & 91.17 & 94.93 \\
\hline
\end{tabular}

